\title{
Variations in the occurrence of SuperDARN F region echoes
}

\author{
M. Ghezelbash ${ }^{1}$, R. A. D. Fiori ${ }^{2}$, and A V. Koustov ${ }^{1}$ \\ ${ }^{1}$ University of Saskatchewan, Saskatoon, Canada \\ ${ }^{2}$ Geomagnetic Laboratory, Natural Resources Canada, Ottawa, Canada \\ Correspondence to: M. Ghezelbash (mohsen.ghezelbash@usask.ca)
}

Received: 29 July 2013 - Revised: 6 December 2013 - Accepted: 14 January 2014 - Published: 20 February 2014

\begin{abstract}
The occurrence of F region ionospheric echoes observed by a number of SuperDARN HF radars is analyzed statistically in order to infer solar cycle, seasonal, and diurnal trends. The major focus is on Saskatoon radar data for 1994-2012. The distribution of the echo occurrence rate is presented in terms of month of observation and magnetic local time. Clear repetitive patterns are identified during periods of solar maximum and solar minimum. For years near solar maximum, echoes are most frequent near midnight during winter. For years near solar minimum, echoes occur more frequently near noon during winter, near dusk and dawn during equinoxes and near midnight during summer. Similar features are identified for the Hankasalmi and Prince George radars in the northern hemisphere and the Bruny Island TIGER radar in the southern hemisphere. Echo occurrence for the entire SuperDARN network demonstrates patterns similar to patterns in the echo occurrence for the Saskatoon radar and for other radars considered individually. In terms of the solar cycle, the occurrence rate of nightside echoes is shown to increase by a factor of at least 3 toward solar maximum while occurrence of the near-noon echoes does not significantly change with the exception of a clear depression during the declining phase of the solar cycle.
\end{abstract}

Keywords. Ionosphere (auroral ionosphere; ionospheric irregularities) - radio science (ionospheric propagation)

\section{Introduction}

The SuperDARN HF radars monitor global-scale plasma convection patterns by measuring the Doppler velocity of coherent echoes received from the $\mathrm{F}$ region ionosphere. An abundance of such echoes is a critical factor for producing reliable convection maps. It has been established that the rate of echo detection with the SuperDARN radars varies with radar location, time of day, season and solar cycle (e.g., Milan et al., 1997; Ruohoniemi and Greenwald, 1997; Koustov et al., 2004; Kane et al., 2012). It has been reported that solar illumination conditions (Bristow et al., 2011), interplanetary magnetic field (IMF) magnitude and orientation (Ballatore et al., 2000), occurrence of magnetic storms (Kumar et al., 2011), and substorms (Wild and Grocott, 2008) affect echo detection. The characteristics of the variations seem to be somewhat different in the northern and southern hemispheres; for example, the southern hemisphere radars show much stronger equinoctial maxima (Koustov et al., 2004). Changes in propagation conditions for radio waves to reach ionospheric irregularities and irregularity production factors have been discussed as reasons for variations in echo occurrence. Although these factors have been identified, their relative role is not well understood and there is no unifying explanation of echo occurrence trends encompassing most of the data.

This study performs a more detailed investigation of the diurnal (magnetic local time, MLT), seasonal and solar cycle variations in the occurrence of $\mathrm{F}$ region echoes detected by the SuperDARN radars than previous studies mentioned in the above paragraph. We focus on the Saskatoon (SAS) radar which has been in operation since late 1993, with very few extended interruptions. The radar is located at magnetic latitude (MLAT) of $\sim 62^{\circ}$ and detects $\mathrm{F}$ region echoes starting from $\sim 68^{\circ}$ MLAT up to polar cap latitudes of $\sim 85^{\circ}$. In addition, this study considers data from several other radars and finally performs an assessment of echo coverage for the entire northern hemisphere SuperDARN radar network over a complete solar cycle and identifies time sectors with better or worse coverage. 


\section{Data selection and processing}

\subsection{Approach}

To assess echo occurrence rates for the SAS radar, we considered data in beams 2 and 3 which are directed toward the geomagnetic pole, Fig. 1a. These meridionally oriented beams were chosen to reduce variability in echo occurrence due to different orientation of the beams with respect to the average convection pattern. Beams 2 and 3 are orientated near the geographic meridian resulting in very little difference between MLT and local time (LT). Only observations in the standard operation mode ( 2 min or 1 min scans) were considered. In practice, there were usually at least $10-15$ days of measurements for each month.

Echo occurrence rate was computed as a ratio of the number of registered echoes in every $45 \mathrm{~km}$ radar resolution cell to the total number of observations in this cell. Ratios were averaged for each $10 \mathrm{~min}$ of observations in magnetic local time and binned in 1-degree bins of magnetic latitude. Magnetic local time was computed by taking into account the geographic coordinates of the center of a radar cell and universal time. Only ionospheric echoes stronger than $3 \mathrm{~dB}$ were counted. Our approach is similar to that of Koustov et al. (2004). For presentation, obtained occurrence rate values were further averaged over $1 \mathrm{~h}$ intervals of each month.

In this study, data from 3 other SuperDARN radars, designed to monitor auroral zone latitudes, are presented. These are the Prince George (PGR) and Hankasalmi (HAN) radars in the northern hemisphere (Fig. 1b, c, respectively), and the Bruny Island TIGER (TIG) radar in the southern hemisphere, Fig. 1d. For these radars we also selected beams oriented roughly along the magnetic meridians, Fig. 1b-d. This ensures that the differences between MLT and LT are minimal, which is not the case for those SuperDARN radars whose fields of view are oriented in an east-west direction. The PGR, HAN and TIG radars were selected because they had been operated continuously for several years over the considered period. Occurrence rates for these radars were computed in the same way as for the SAS radar. Echo occurrence data for the entire SuperDARN network will also be presented. Here the total number of points on each individual 2 min convection map was considered.

\subsection{Latitudinal profile of echo detection}

Figure 2 shows SAS dusk (17:00-19:00 MLT) and noon (11:00-13:00 MLT) echo occurrence rates at all available magnetic latitudes for observations between 1994 and 2012, for every second (even) year. Data presentation was limited to even years of observations to simplify the plot; fewer data allows one to more easily recognize both general trends within the solar cycle and minor variations within an individual year. Similar plots were produced for other time sectors. For the dusk sector, the latitudinal spread of enhanced echo

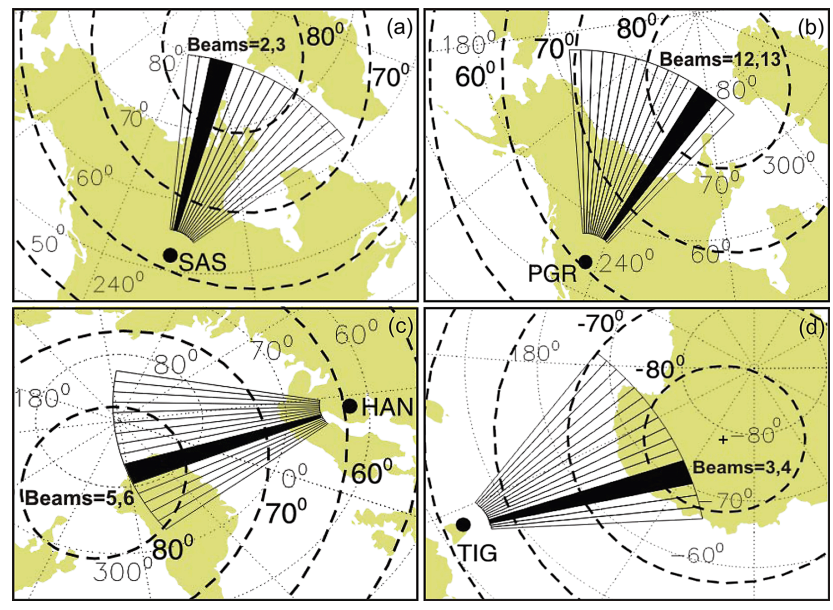

Fig. 1. Field of views of the (a) Saskatoon (SAS), (b) Prince George (PGR), and (c) Hankasalmi (HAN) SuperDARN radars in the northern hemisphere and (d) Bruny Island TIGER (TIG) SuperDARN radar in the southern hemisphere. The beams considered (labeled by numbers) are shaded by black.

occurrence is larger than for other time sectors, and this is why these data are presented in Fig. 2a. For the noon sector, Fig. 2b, latitudinal coverage is smaller and changes from year to year are not as strong as for the dusk sector. Figure 2 indicates it is important to consider observations in various sectors separately.

According to Fig. 2a, at low MLATs of $<68^{\circ}$ where echoes are most likely coming from the E region the maxima are recognizable as "patches" of light blue-greenish color. These are not as strong (with the exception of 1994) as echo occurrence patches with red color at higher latitudes, which correspond to $\mathrm{F}$ region echoes.

Patches of enhanced $F$ region echo occurrence $\left(\right.$ MLAT $>\sim 68^{\circ}$ ), presented in Fig. 2a, exhibit highest values during the 1998-2004 interval, i.e., during the years of strong solar activity. Overall, rates are enhanced at MLATs of $\sim 68^{\circ}-84^{\circ}$. However, the latitudinal extent of this band changes with season and solar cycle. This is contrary to the near noon data of Fig. $2 b$ where the band does not shift much within the solar cycle. Because of this variability from year to year and dependence on the time sector, echo occurrence for the SAS radar was characterized by considering observations at all magnetic latitudes between $68^{\circ}$ and $84^{\circ}$. We note that the SAS echo occurrence rates at MLAT $>84^{\circ}$ are low. We have also performed analysis of occurrence rates by considering narrower latitudinal ranges including adoption of different latitudinal bands of echo detection on the dayside and nightside. Results of these analyses will not be presented here; they are largely consistent with our report below. For other radars, the echo band extent was selected through similar considerations. 


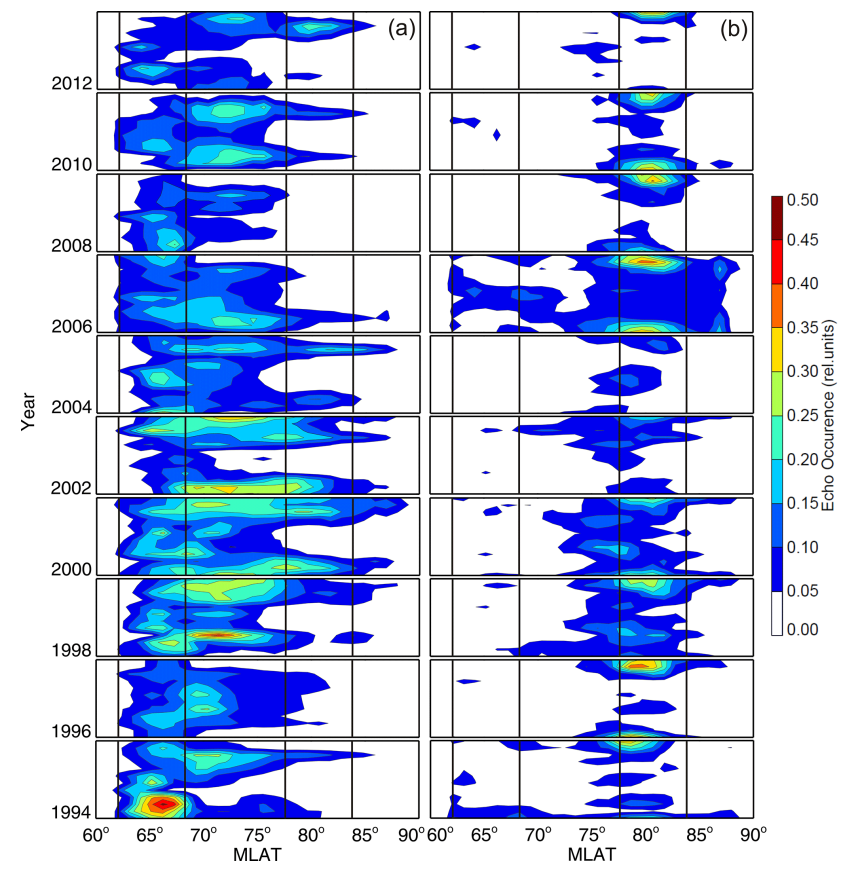

Fig. 2. Saskatoon SuperDARN radar echo occurrence rates at all available magnetic latitudes in the dusk sector (17:00-19:00 MLT) and noon (11:00-13:00 MLT) for the even years in the period of 1994-2012.

\section{Data presentation}

\subsection{Hourly occurrence rates}

Figure 3 is a contour plot of hourly-averaged (over each month) occurrence rate for SAS radar observations during (a) minimum solar cycle activity (2008-2010) and (b) maximum solar cycle activity (2000-2002) in terms of month and MLT. For solar minimum (Fig. 3a), there is a clear pattern of a change in the location of maximum echo occurrence. In each year the pattern resembles a diamond having peak occurrence near noon in the winter months and near midnight in the summer months. Echoes occur less frequently during summer months near noon and winter/equinox months near midnight. The pattern is repetitive from one year to another. The pattern is less developed for dawnside observations (00:00-12:00 MLT), as is evident by the stronger occurrence rates (light blue and green) on the duskside of the plot (12:00-24:00 MLT). One can notice, although not very clearly, that blobs of enhanced echo occurrence in Fig. 3a are located close to equinoctial dusk time (months 3 and 9, at 18:00 MLT).

There is a different pattern for solar maximum (Fig. 3b). Echo occurrence also follows a diamond-like structure. The boundary between high and low echo occurrence rate mark the edges of the diamond; regions of low echo occurrence (blue color) and high echo occurrence constitute the interior and exterior of the diamond, respectively. Overall, echo

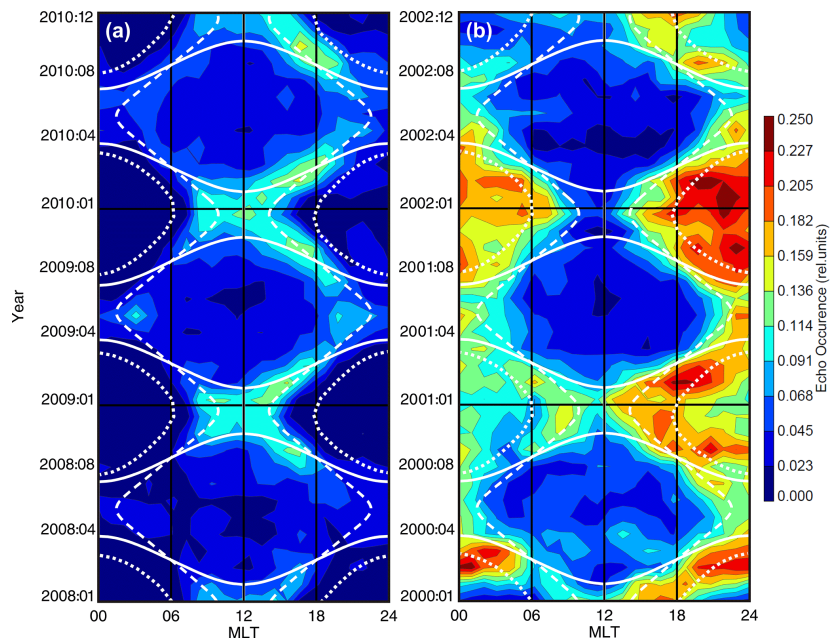

Fig. 3. Saskatoon SuperDARN radar echo occurrence for periods of (a) minimum solar activity (2008-2010) and (b) maximum solar activity (2000-2002) as a function of MLT time. Data in beams 2, 3 and magnetic latitudes of $F$ region echo detection $\left(68^{\circ}-84^{\circ}\right)$ were considered. The dashed and solid white lines represent the terminator line at the earth's surface for MLAT $=72^{\circ}$ and $82^{\circ}$, corresponding roughly to the expected centers of echo bands for one-half-hop and 1.5-hop propagation modes, respectively. The white dotted line shows seasonal variation of an ionospheric point with constant solar zenith angle of $108^{\circ}$ (corresponding to a sunset at the height of $\sim 300 \mathrm{~km}$ ) at MLAT $=72^{\circ}$ (a similar line for MLAT $=82^{\circ}$ differs from the dotted line insignificantly and not shown).

occurrence rate is larger in all regions compared to Fig. 3a. Echo occurrence rates are maximized (dominance of red color) on the nightside ( $\sim$ 18:00-06:00 MLT). During winter months maximum echo occurrence extends toward noon hours. Largest occurrence rates are observed during equinoctial dusk-to-midnight hours. These equinoctial maxima are more evident than those in Fig. 2a because they are more extended in MLT.

In both Fig. 3a, $b$ the white dashed and solid lines indicate the location of the terminator line (at the surface of the earth) for magnetic latitudes of $72^{\circ}$ and $82^{\circ}$, respectively. These latitudes are roughly the typical latitudes of SAS echo detection via one-half $-\left(68^{\circ}-77^{\circ}\right)$ and $1.5-\left(77^{\circ}-84^{\circ}\right)$ hop propagation modes as defined after Milan et al. (1997). One can treat this line as the one for the solar zenith angle of $90^{\circ}$. We also show here seasonal variations of an ionospheric point within the radar FoV with constant solar zenith angle of $108^{\circ}$ at MLAT $=72^{\circ}$. The line roughly describes the sunset time at the height of $\sim 300 \mathrm{~km}$ for various months. A similar line for MLAT $=82^{\circ}$ is not shown here because it has only minor differences with the dotted line. The significance of the terminator/sunset lines will be discussed later. 


\subsection{Solar cycle effects in the noon and midnight sectors}

Data of Fig. 3 indicate that the echo occurrence rates vary with the magnetic local time of observations, and the character of the "season-MLT" pattern changes as the solar cycle progresses. The contrast in absolute values of occurrence is very obvious for the midnight sector and not so in the noon sector. We investigate this effect in more details.

Figure 4 shows season-averaged occurrence rates for every year of SAS observations since 1994 along with seasonaveraged $10.7 \mathrm{~cm}$ flux of solar radiation, characterizing the solar cycle phase. Data for near noon (11:00-13:00 MLT) and near midnight (23:00-01:00 MLT) are presented separately. Near noon (Fig. 4b), data for summer (red line) and spring equinox (black solid line) months do not indicate a long-term trend. In contrast, winter observations (blue line) show a depression in occurrence rate in 2003-2004, immediately following the solar cycle maximum $(\sim 2001-2002)$, on the declining phase of the solar cycle 23 . Interestingly enough, toward the solar cycle 24 maximum (2012), the occurrence rate drops again. For the fall equinox (black dotted line), the occurrence rates are depressed during years of solar cycle maximum, anti-correlating with the $10.7 \mathrm{~cm}$ radio flux changes.

Near midnight (Fig. 4c), variations of the echo occurrence are the same for all seasons with about a 3-fold increase toward the solar cycle maximum. It is interesting that the occurrence rates are largest during summer months for periods of solar cycle minimum and summer and equinoctial months for periods of solar cycle maximum. We note that the dusk and dawn sector data show the smallest solar cycle increase.

\subsection{Results for other radars and the entire SuperDARN network}

Recently, Kane et al. (2012) investigated the TIG (Bruny Island) SuperDARN radar data in the southern hemisphere and identified a pattern of enhanced $\mathrm{F}$ region echo occurrence on the month-MLAT plane. The pattern (that they termed "butterfly") is very similar to the pattern we report here for the SAS radar with an offset in appearance because the first month of the year is summer in the southern hemisphere while it is winter in the northern hemisphere. There are some SAS-TIG differences that will be discussed here. To identify these differences, TIG data were processed similarly to the SAS data (Fig. 3a, b) for the same time periods. We considered data in meridionally oriented beams of 3 and 4 (Fig. 1d). The results are shown in Fig. 5a, b. Figure 5 is a contour plot of hourly-averaged (over each month) occurrence rate for TIG radar observations during (a) minimum solar cycle activity (2008-2010) and (b) maximum solar cycle activity (2000-2002) periods in terms of month and MLT. The differences between observations of SAS (Fig. 3a, b) and TIG (Fig. 5a, b) are as follows.

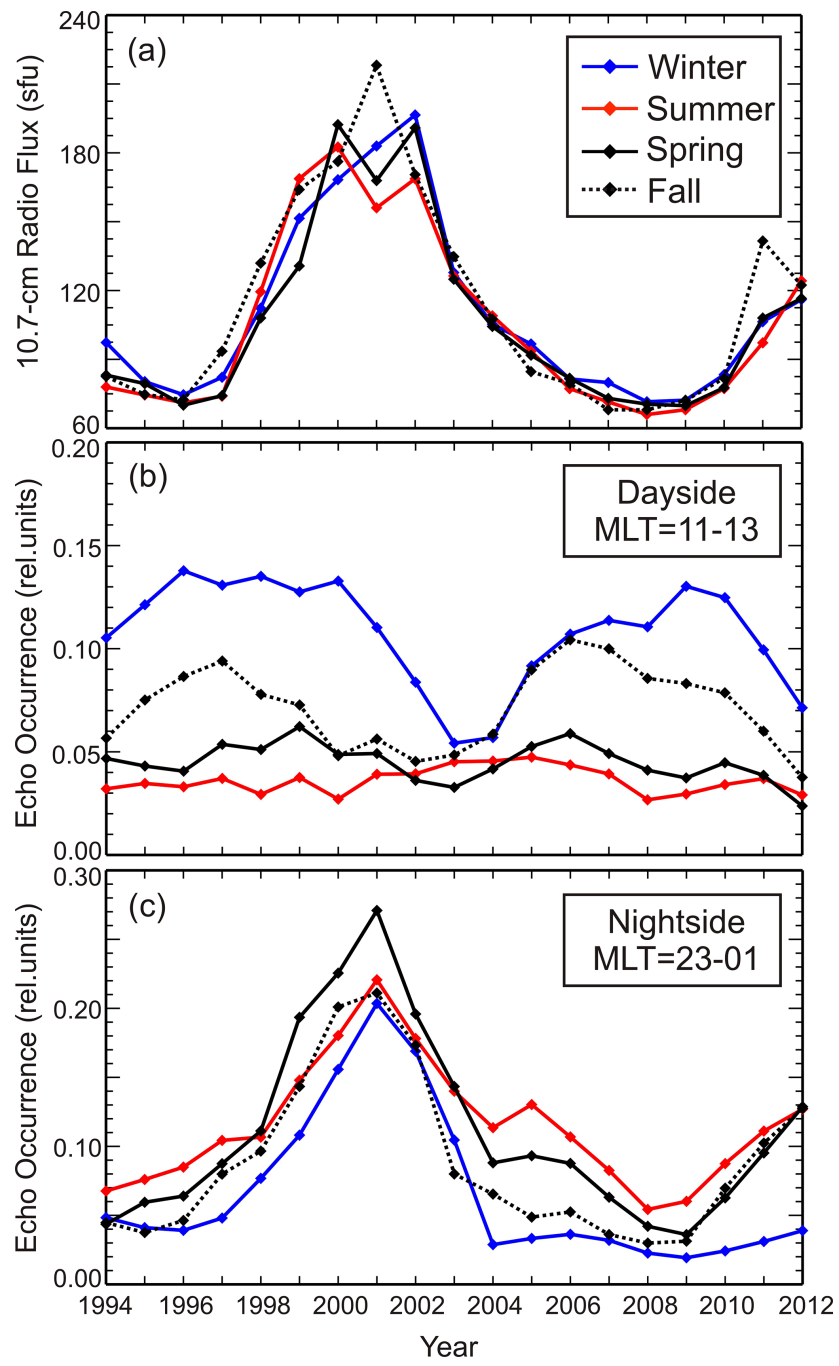

Fig. 4. Season-averaged (a) $10.7 \mathrm{~cm}$ radio flux; (b) SAS radar echo occurrence for observations near noon hours (11:00-13:00 MLT); (c) SAS echoes near midnight hours (23:00-01:00 MLT). All data in the period of 1994-2012 were considered. The $10.7 \mathrm{~cm}$ radio flux data were provided by National Geophysical Data Center (http:// www.ngdc.noaa.gov/).

1. During solar minimum years (2008-2009), the TIG radar shows less contrast in occurrence rates between near-noon winter and near-midnight summer echoes and between rates for the 00:00-12:00 MLT and 12:00-24:00 MLT sectors. The TIG data often show a clear enhancement of echo occurrence during equinoctial months for both dawn and dusk hours. The TIG data show local depressions in echo occurrence around noon.

2. During solar maximum years (2001-2003), the TIG winter nighttime echo increase (from summer to winter) is not as strong as for SAS. 
3. The TIG data do not show as drastic a change in the shape of the echo occurrence pattern over the solar cycle.

Another difference between TIG and SAS, identifiable from long-term data records (beyond what is shown in Fig. 5) is that although TIG shows a decrease in near-noon echo occurrence rates away from the solar cycle maximum, a subsequent recovery toward the next solar cycle 24 maximum (as is seen for SAS in Fig. 4, blue line) does not happen.

Despite the above differences between the SAS and TIG data, the overall pattern of echo occurrence on the "monthMLT" plane is the same, especially for solar minimum conditions.

A natural question is whether the pattern is a common feature for other SuperDARN radars. We processed data for a number of other northern hemisphere radars and found very similar features for the PGR, HAN, Rankin Inlet and Inuvik radars. As additional examples, we present PGR and HAN radar data in Fig. 5c-f. For the solar minimum period, both plots show a "diamond-like" pattern. The winter near-noon maxima are much stronger for PGR, and are shifted to the pre-noon hours. HAN occurrences are the smallest out of the three northern hemisphere radars considered, but the pattern is remarkably the same. For the solar maximum period, the patterns on both plots show strong occurrence enhancement during winter near-midnight hours. On a finer scale, the patterns of these near-midnight enhancements are somewhat different. The PGR pattern is closer to that of TIG with local depressions in occurrence during the middle of winter (November-December). The HAN pattern is closer to that of SAS with a strong enhancement during the entire winter. The HAN radar shows the strongest contrast between summer near-noon and winter near-midnight echo occurrences. Judging by color in Fig. 5c-f, the 00:00-12:00 MLT occurrences are slightly smaller, overall, than 12:00-24:00 MLT occurrences for PGR and they are about the same for HAN.

Since the inferred pattern of seasonal and MLT/LT variations in echo occurrence seems to be similar for at least several northern hemisphere and one southern hemisphere SuperDARN radars, we hypothesized that it might be seen in data for the entire network. To explore this hypothesis, we plot in Fig. 6 total number of grid points in terms of month and MLT over the years of minimum and maximum of the solar activity. In Fig. 6 (and later in Fig. 7) the data are binned differently as compared to our previous diagrams. "Grid points" are the standard SuperDARN bins of geomagnetic latitude and longitude $\left(1^{\circ}\right.$ in MLAT and $\sim 111 \mathrm{~km}$ in MLON) as introduced by Ruohoniemi and Baker (1998). Figure 6 was obtained by counting total number of echoes in $1 \mathrm{~h}$ MLT sectors at all magnetic latitudes for all northern hemisphere radars. Note that data were initially filtered to remove contributions from $\mathrm{E}$ region echoes by only considering echoes at ranges of $>630 \mathrm{~km}$.
Data for solar cycle minimum (2008 and 2009) show a "diamond-like" pattern of increased number of points, consistent with the pattern of increased echo occurrence in Figs. 3a and 5a, c, e. Here the pattern for 2010 is more confusing, but afternoon-dusk "shoulders" of a diamond-like pattern are recognizable by red sloped regions. For solar cycle maximum, the pattern of Fig. $6 \mathrm{~b}$ is reminiscent of that shown in Figs. $3 b$ and $5 b, d, f$ for the occurrence rate, with clear enhancements during winter near-midnight hours. A decrease in the number of near-noon summer echoes is obvious for both cases. Since all the SuperDARN radars and all radar beams and magnetic latitudes were considered in producing of Fig. 6, the data suggest that the existing SuperDARN radars have a more-or-less common pattern in the variation of echo occurrence with MLT, season and solar cycle.

\section{Discussion}

Despite the significant database accumulated for the SAS radar, its echo occurrence rates have not been investigated in many aspects. Huber (1999) explored Saskatoon radar data for 1997 and reported that wintertime $\mathrm{F}$ region echoes are mostly detected in two time sectors: near noon and later in the afternoon close to the dusk sector. Hosokawa et al. (2001) merged SAS data with data from other Canadian radars for periods of solar minimum and showed that winter and summer time echoes are more frequent on the dayside and nightside, respectively. They also noticed a separate region of enhanced echo detection in the afternoon-dusk sector and related those to the sectors of favorable conditions for the gradient drift instability operation in the ionospheric trough which is highly expected at these latitudes and during these hours. Koustov et al. (2004) considered SAS observations near midnight for years 1996-2001 (i.e., from the minimum to the maximum of solar cycle 23). The paper focused on two discrete bands of magnetic latitude, $70.5^{\circ}$ and $75.5^{\circ}$. The authors found evidence for equinoctial maxima; they were more obvious at the solar minimum and at lower latitudes. Danskin (2004) reported that Hankasalmi midnight echoes are more frequent for summer months during solar minimum and winter months during solar maximum. During transitional years, equinoctial maxima were evident. Liu (2010) considered data averaged over $24 \mathrm{~h}$ for 2007 and showed that at far ranges of echo detection, through 1.5-hop propagation mode, the SAS equinoctial maxima are much stronger than at near ranges of echo detection, through one-half-hop propagation mode. Overall the seasonal variation was not found to be strong.

In this study we expanded analysis of the SAS radar data in terms of time (until 2012), in terms of latitude (up to MLATs $\sim 84^{\circ}$ ) and considered data for other sectors of SAS observations. We showed that during the solar cycle minimum, the pattern of echo occurrence was quite clear with 


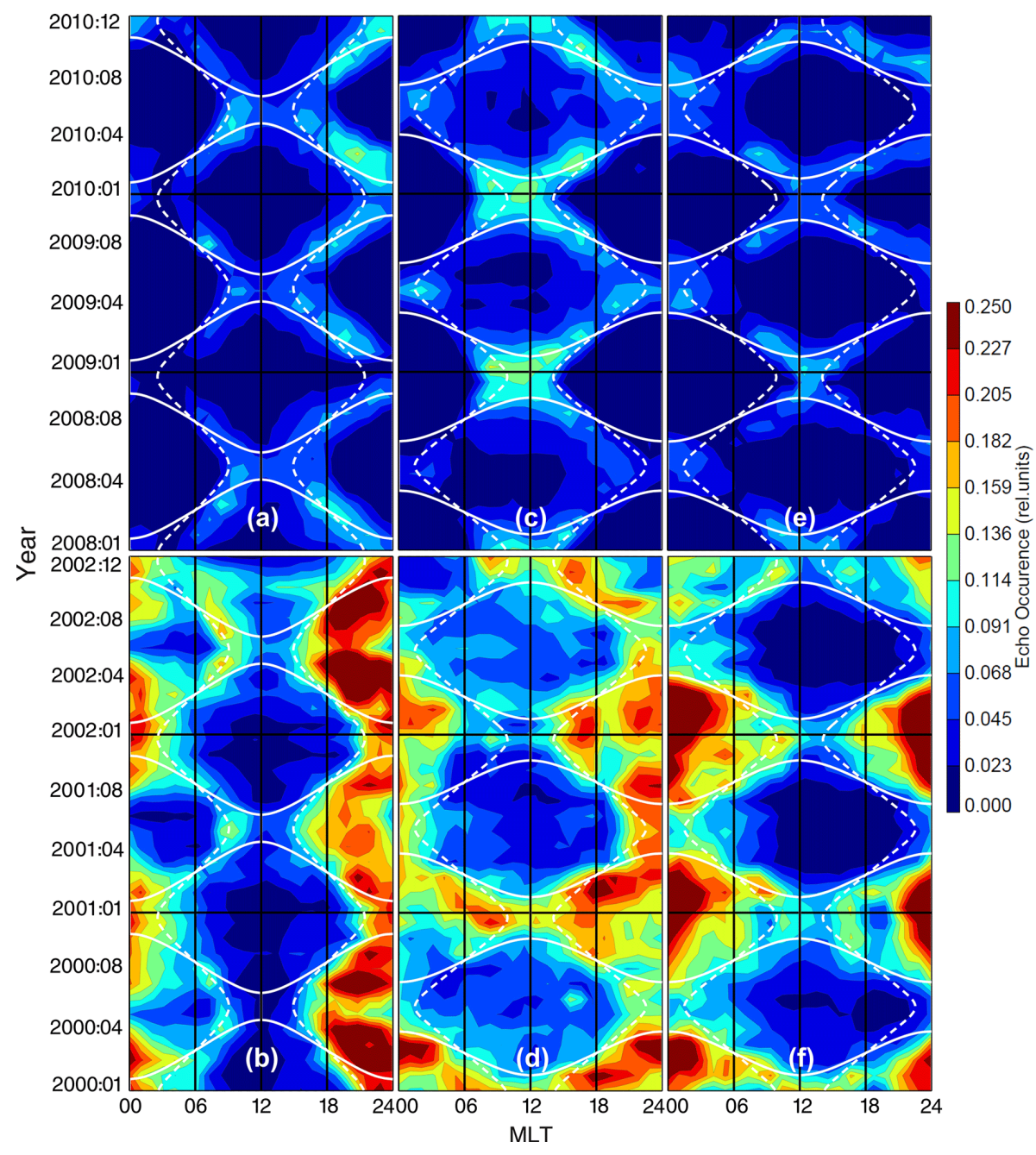

Fig. 5. Echo occurrence rates for periods of minimum solar activity (2008-2010, top row) and maximum solar activity (2000-2002, bottom row) as a function of MLT time for the Bruny Island (TIG, a and b), Prince George (PGR, $\mathbf{c}$ and d) and Hankasalmi (HAN, e and f) SuperDARN radars. Roughly meridional beams for each radar were considered as indicated in Fig. 1b, c, d. Only magnetic latitudes of $\mathrm{F}$ region echo detection were considered. The dashed and solid white lines represent the terminator line at the earth's surface for, roughly, the expected centers of the one-half-hop and 1.5-hop echo bands.

maxima of occurrence located along a diamond with corners located near noon for winter months and near midnight for summer months. We note that Milan et al. (1997) considered a limited data set of the early Hankasalmi SuperDARN observations and found that during winter, the radar echoes at MLAT $=80^{\circ}$ are mostly detected during daytime with two local maxima, one during pre-noon hours and another during post noon hours. The maxima appear to become more separated in terms of time towards summer time. The plots of Fig. 3 for SAS and Fig. 5c-f for HAN and PGR are thus consistent with the finding of Milan et al. (1997). Our analysis of the entire HAN database showed one interesting and important difference in the HAN plots: the overall echo occurrence is comparable or even slightly larger on the dawnside (00:0012:00 MLT) than on the duskside (12:00-24:00 MLT).
Our analysis showed that for the SAS radar, near-noon echoes are more frequent during winter (and at solar cycle maximum). Preferential occurrence of winter echoes over other seasons can be explained by improved propagation conditions (especially critical for 1.5 -hop propagation mode) during this season due to the "winter anomaly" effect, a strong enhancement in the near-noon F region electron density at middle latitudes. This provides good conditions for radio waves to bounce from the ionosphere and be reflected forward. Enhanced electron density in the scattering regions, which is essential in the polar cap for observations near noon, is also important. Density is stronger for summer conditions (Ghezelbash, 2013). For summer observations, however, besides generally smaller densities near the radar wave bending region, the sunlight effect of smoothing the ionospheric gradients plays an important role, as concluded for example 


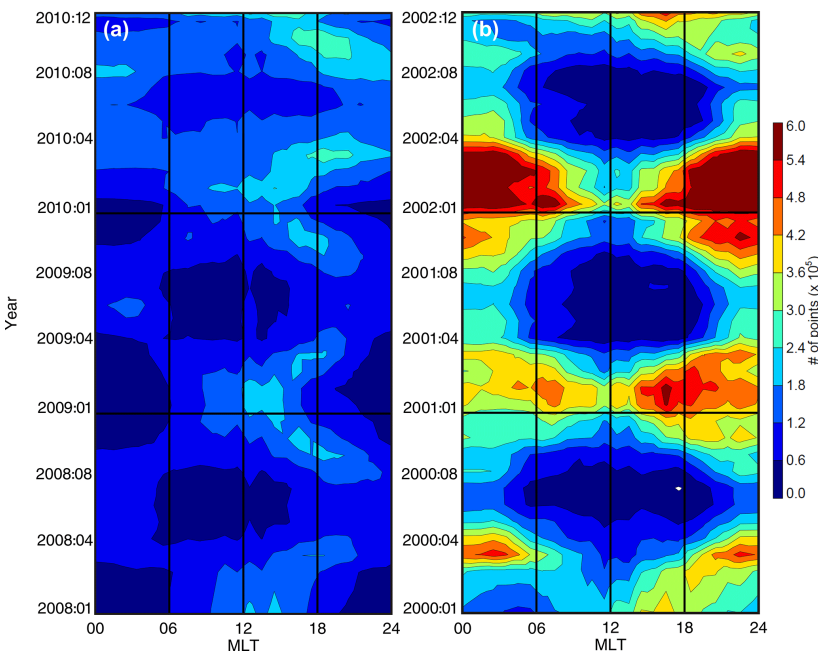

Fig. 6. Contour plot for the total number of grid points on SuperDARN convection maps (cumulative over all magnetic latitudes of echo detection) for observations in the periods of (a) minimum solar activity (2008-2010) and (b) maximum solar activity (2000-2002) as a function of MLT time.

by Ruohoniemi and Greenwald (1997). Figure 3 shows that the winter-summer contrast in echo occurrence is larger during solar maximum. This is consistent with the fact that the winter anomaly becomes stronger during solar maximum. In terms of the MLT/LT effect, a decrease of winter echo occurrence away from the near-noon hours can be related to the decrease of the electron density in the dark polar cap winter ionosphere (Ghezelbash, 2013).

In terms of diurnal variation, the SAS radar showed enhanced echo occurrence during noon-dusk hours. Kane and Makarevich (2010) explained a similar effect for the TIG radar by improved propagation conditions (refraction) during these hours. Similar explanations can be used for the SAS data presented in the current study. As mentioned, the HAN radar does not show such a strong contrast between pre-noon and afternoon occurrences (Fig. 5e, f). This seems to be inconsistent with the explanation of Kane and Makarevich (2010), but we discovered that within the HAN field of view (FoV), F region electron density is typically larger during pre-noon hours (the density data for the Sodankyla ionosonde, within the HAN FoV, can be found in Ghezelbash, 2013).

Thus the near-noon SAS data indicate that propagation condition is the most important factor for echo detection in this sector of observation. Milan et al. (1998) argued that near noon the echo band covers about the same MLATs irrespective of whether the echoes are received through a onehalf-hop or 1.5-hop propagation path. In a sense, the radar echo band reflects the physical boundaries in the ionosphere within which there are enhanced fluctuations of the electron density (ionospheric irregularities). This effect, with more extended database, covering both years of the solar cycle

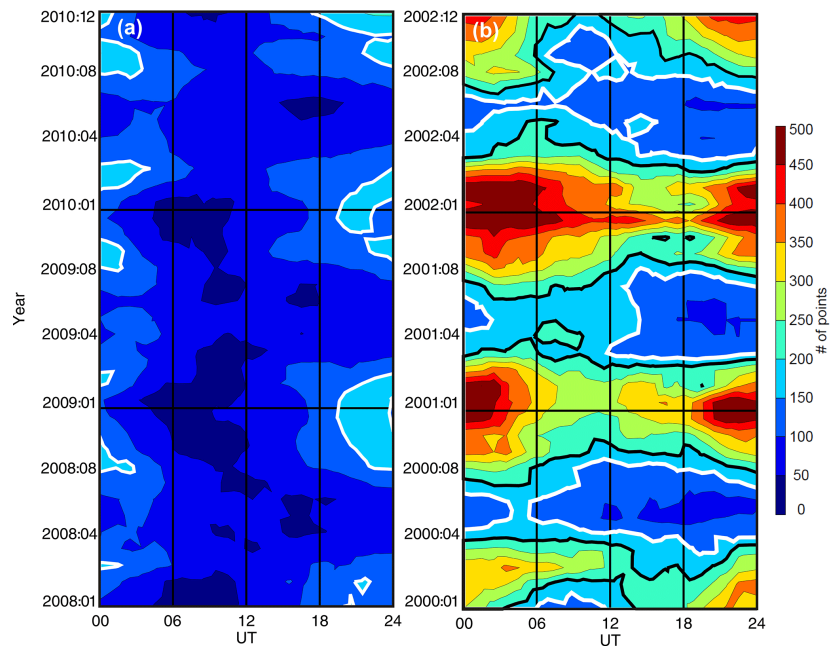

Fig. 7. Contour plot for the hourly-averaged number of grid points on individual 2 min SuperDARN convection maps for periods of (a) minimum solar activity (2008-2010) and (b) maximum solar activity (2000-2002) as a function of UT time. The white line is the contour with the number of points at 150 (both panels) and 200 (panel b); in regions with a lower number of points a SuperDARN convection map based on the data is expected to be globally unreliable.

minimum and maximum, is well seen in the data of Fig. $2 b$. Figure $2 b$ indicates that the band of near-noon echoes does not shift much within the solar cycle. The TIG data are also consistent with this conclusion except the band becomes much wider during solar cycle maximum. We believe that the SAS, HAN, PGR and TIG observations do not contradict our conclusion on the primary role of propagation conditions as we investigate the overall echo occurrence at all latitudes.

If the occurrence of near-noon echoes is indeed strongly controlled by propagation factors, we have to relate the depression in occurrence of noon winter and spring equinox echoes near/right after the solar cycle maximum (Fig. 3) reported in this study with a deterioration of propagation conditions. We are not aware of evidences that would support this conclusion. If we adopt the notion by Milan et al. (1998), mentioned above, we must conclude that the irregularity production deteriorates during these periods as well. It is hard to understand why this would happen. Information on electric field variations and plasma gradient creation over the solar cycle is needed to assess this possibility.

Our next comment is with respect to nightside observations. Echo detection on the nightside is more likely due to one-half-hop propagation mode. The enhanced electron density is required to meet orthogonality condition. The density effect in occurrence of HF echoes was well demonstrated by Kane et al. (2012) for the TIG radar. The authors also explained that enhanced echo detection in the post noon to midnight sectors is maintained because $\mathrm{F}$ region density decreases slowly while the E region density decays quickly (which removes the shortening effect on the polarization 
electric field on the gradient-drift instability in the $\mathrm{F}$ region, see e.g., Tsunoda, 1988). Both the effects and the explanation are applicable to our case for the SAS radar. Also, less frequent echo occurrence in the post-midnight and morning sectors can occur due to enhanced radio wave $\mathrm{D}$ region absorption associated with substorm activity in the midnight sector. All these effects can explain the asymmetry in echo occurrence for the 00:00-12:00 MLT and 12:00-24:00 MLT periods.

An interesting question is on the role of the terminator/sunset lines in the occurrence pattern on the "monthMLT" plane. For periods of solar minimum, the terminator line is within/close to the region of maximum echo detection rate for the one-half-hop propagation mode, Figs. 3 and 5. The $300 \mathrm{~km}$ sunset line reflects a significant drop in echo occurrence (transition from dark blue to light blue). This probably means that the ionosphere near the terminator (the so called "grey" ionosphere as known to radio amateurs) provides the best propagation conditions for HF radio waves, and this is the major factor in the frequent detection of HF echoes. The 1.5-hop propagation mode signals are mostly observed in the dark ionosphere but still for the periods with smallest solar zenith angle (Figs. 3 and 5). Having no direct sunlight is advantageous in terms of "hiding" the ionosphere (essentially, the polar cap ionosphere) from the harmful effect of the solar radiation on irregularity production, an effect that was very clearly articulated by Ruohoniemi and Greenwald (1997) for the Goose Bay radar. On the other hand, no solar radiation and a less dense ionosphere would not allow for sufficient refraction and strong enough backscattered echo power (e.g., Bristow et al., 2011). The high echo detection rates near-noon (mostly through 1.5-hop propagation mode) means there is a certain balance between these factors.

For periods of solar maximum, Kane et al. (2012) noticed that the terminator line is not really a special line on the occurrence plots as echoes are equally frequently detected well prior and well after the sunset. This is despite the fact that only quiet days were selected in their paper. In our analysis all observations were considered, and the terminator line is a separation line between the sectors of highest and relatively low echo occurrence. The $300 \mathrm{~km}$ sunset line does not indicate a significant change in echo occurrence during nighttime of 2001-2002, from the fall equinox to winter and to spring equinox. This result is consistent with that of Kane et al. (2012). For other two winter times of Fig. 3b (JanuaryMarch 2000, September 2000-March 2001 and SeptemberDecember 2002) the line is not far from the periods of a sharp decrease in echo occurrence (a transition for red to yellow). This is different from the report by Kane et al. (2012). Our results imply that during the solar cycle maximum there are additional factors (besides transition from sunlit to dark ionosphere) controlling the onset of $\mathrm{F}$ region echoes. Koustov et al. (2004) argued that increases in the occurrence of strong plasma gradients and electric fields are potentially two additional factors for nighttime observations. Unfortunately, there is no obvious way to check the validity of this hypothesis although there are several indirect arguments. First of all, it is well established that the cross polar cap potential, that drives the ionospheric plasma globally, correlates well with the IMF $B_{z}$ component (e.g., Fiori et al., 2009). Near-solar cycle maximum, large IMF $B_{z}$ values occur more frequently and one would expect generally faster convection flows/electric fields in the ionosphere. Secondly, it is known that particle precipitation and aurora occurrence are more frequent during solar cycle maximum.

Another interesting question is whether the $\mathrm{F}$ region echo occurrence shows equinoctial maxima. Koustov et al. (2004) reported the effect to be strongest for Syowa East (SYE) and Halley (HAL) radars in the southern hemisphere and less pronounced for the HAN and North American radars in the northern hemisphere for observations near midnight. Data presented in this study allow us to look at the issue with more details.

We first consider the SAS data. During years of solar maximum, 2000-2002, enhanced echo occurrence at equinoxes is recognizable in the dusk-midnight sector of 18:00-24:00 MLT, Fig. 3b. In the midnight-dawn sector, 00:00-06:00 MLT, the equinoctial maxima are seen in the spring of 2000 and 2002, but are not so obvious in 2001. Fall enhancements are hardly recognizable. The equinoctial maxima are not distinct for the minimum of the solar activity in the dawn sector (Fig. 3a). The echo occurrence here is stronger during noon hours in winter and dusk hours in equinoctial months. Data for the TIG and PGR radars (Fig. 5b, d) show equinoctial maxima for 2000 and 2002 and a hardly recognizable maxima for 2001. Again, some signatures of the equinoctial maxima are identifiable for years of the solar activity minimum. Surprisingly, all these features are almost impossible to see in the HAN data (Fig. 5e, f). In an attempt to resolve this inconsistency, data were processed for the southern hemisphere HAL and SYE radars that have been in operation in 2000-2002 and 2008-2010. In agreement with Koustov et al. (2004), the HAL and SYE radars show much more obvious equinoctial maxima than the northern hemisphere radars and the TIG radar. However, the HAL and SYE radars do not show the enhancements of echo occurrence near noon hours during winter observations. This is due to poor propagation conditions as the field of view of these radars are in the dark ionosphere (this is consistent with an opinion of Bristow et al. (2011), who considered McMurdo data). We can conclude that the SAS data presented here are consistent with what has been reported in the past; signatures of the equinoctial maxima do present but they are not always recognizable for periods of solar cycle minimum. The strength of the maxima varies from one radar to another.

In this study is was found that the pattern of the entire SuperDARN network echo coverage in terms of month and MLT of observation is similar to that of the SAS radar alone. If the inferred pattern of SAS echo occurrence is indeed "generic" and applicable to every individual SuperDARN 
radar, then, statistically speaking, time sectors with better/worse radar coverage can be identified for individual convection maps, no matter how many SuperDARN radars are operational. One can infer from Fig. 6 that the sectors of weaker occurrence are located near noon for summer time observations during solar maximum periods. For the solar minimum conditions, the echoes occur less frequently near midnight for winter months and near noon for summer months. Having periods with decreased echo coverage for the entire network does not mean that an increase in the number of SuperDARN radars is not needed; it only points to regions where SuperDARN convection patterns will be less reliable. In fact, an increase in the number of SuperDARN radars is highly desirable. To illustrate this statement, Fig. 7 plots the average number of points per SuperDARN convection map in terms of month and UT of observation for the same periods considered in this paper. We note that the number of points per map is a very important parameter in SuperDARN work. While studying the SuperDARN cross polar cap potential, Mori and Koustov (2013) discovered that for this parameter not to be affected by the startup convection model (and thus to have a globally reliable convection pattern) one has to have at least 200 points on each map. We attempted to put the 200 point contour on both plots of Fig. 7 but discovered that for the minimum of solar activity period the closest reasonably identifiable contour was 150 points. The 150 point contour has therefore been enhanced in Fig. 7a. For solar maximum conditions we selected the 200-point contour (Fig. 7b). In Fig. 7b, near the solar cycle maximum (2000-2003), maps consistently have $>200$ points, with the exception of summer months. The situation changes dramatically for periods of solar minimum (Fig. 7a). Here maps are only expected to be reliable for near midnight in the winter periods and for early morning (right after midnight) in the near-equinoctial periods. We have to stress here that the pattern on Fig. 7 is effectively a longitude/geographic variation, given that the data are now averaged over all available MLTs. Therefore, the variations in this figure are not due to geophysical differences betwee the local time, but are likely to be due to the uneven distribution of radars with longitude (first of all, a significant gap in Russian sector of Arctic). Data of Fig. 7a, b thus clearly indicate that further improvement of the quality of the SuperDARN convection mapping can only be achieved through the installation of additional radars. This process is under way with recent installation of new radars in both hemispheres. This expansion improves radar coverage of higher and lower magnetic latitudes. Although this is a very important development, our analysis indicates that improvement of the longitudinal coverage is more desirable, as far as global convection pattern monitoring is concerned.

\section{Conclusions}

In this study we investigated the $\mathrm{F}$ region echo occurrence rates for a number of SuperDARN HF radars with an emphasis on the Saskatoon SuperDARN radar data for 1994-2012. We showed the following:

1. Echo occurrence experiences significant diurnal, seasonal and solar cycle variations. Patterns of echo occurrence in terms of month and MLT of observation are highly repetitive. For solar cycle minimum conditions, the pattern has maxima during winter noon hours, equinoctial dusk/dawn hours and summer midnight hours. For solar cycle maximum conditions, the pattern changes drastically with most echoes being observed during nighttime for all seasons with more extended periods of time during winter.

2. While nighttime echo occurrence increases by at least a factor of 3 toward the solar cycle maximum, the nearnoon echo occurrence does not significantly change for summer and fall equinox and there is a very clear depression on the declining phase of the solar cycle for winter and spring equinox.

3. By considering the number of grid points available for the entire SuperDARN network in various MLT sectors and all magnetic latitudes, we showed that the pattern of increased number of points in "month-MLT" coordinates is essentially the same as the pattern of increased echo occurrence of the Saskatoon radar alone. This means that the network has decreased coverage for all MLTs of summer time during periods of solar maximum and near midnight for winter months and near noon for summer months during periods of solar minimum.

4. Because each SuperDARN radar has a very specific pattern of preferential echo occurrence in "monthMLT" coordinates, and the radars of the network are very unevenly distributed in longitude, individual convection maps have significant data gaps making the maps unreliable in global sense, at certain UT times and for certain seasons. Improvement of the longitudinal SuperDARN radar coverage through installation of radars in Russian sector of Arctic is highly desirable (perhaps even more desirable than extension of the latitudinal coverage) to improve the quality of globalscale convection mapping. 
Acknowledgements. The Saskatoon SuperDARN radar operation is jointly funded by the Canadian Space Agency and NSERC (Canada). The research is supported by an NSERC Discovery grant to A. V. Koustov. Operation of northern hemisphere SuperDARN radars is supported by funding agencies of Canada, France, Japan, the UK and the US. Operation of the Bruny Island TIGER radar in the southern hemisphere is supported by a consortium of institutions: La Trobe University, University of Newcastle, Monash University, Australian Antarctic Division, ISR Division DSTO and IPS Radio and Space Services. The $10.7 \mathrm{~cm}$ radio flux data are provided by National Geophysical Data Center (http://www.ngdc.noaa.gov/). The authors thank P. V. Ponomarenko for numerous comments, help in computations and suggestions in the process of this work. Criticism and suggestions of the reviewers are appreciated.

Topical Editor K. Hosokawa thanks D. Danskin and one anonymous referee for their help in evaluating this paper.

\section{References}

Ballatore, P., Villain, J. P., Vilmer, N., and Pick, M.: The influence of the interplanetary medium on SuperDARN radar scattering occurrence, Ann. Geophys., 18, 1576-1583, doi:10.1007/s00585001-1576-2, 2000.

Bristow, W. A., Spaleta, J., and Parris, R. T.: First observations of ionospheric irregularities and flows over the south geomagnetic pole from the Super Dual Auroral Radar Network (SuperDARN) HF radar at McMurdo Station, Antarctica, J. Geophys. Res., 116, A12325, doi:10.1029/2011JA016834, 2011.

Danskin, D. W.: HF auroral backscatter from the E and F regions, Ph.D. Thesis, University of Saskatchewan, available at: http://hdl.handle.net/10388/etd-10242003-121305 (last access: 17 February 2014), 2004.

Fiori, R. A. D., Koustov, A. V., Boteler, D., and Makarevich, R. A.: PCN magnetic index and average convection velocity in the polar cap inferred from SuperDARN radar measurements, J. Geophys. Res., 114, A07225, doi:10.1029/2008JA013964, 2009.

Ghezelbash, M.: Occurrence and causes of F-region echoes for the Canadian PolarDARN/SuperDARN radars, M.Sc. Thesis, University of Saskatchewan, available at: http://hdl.handle.net/ 10388/ETD-2013-03-949 (last access: 17 February 2014), 2013.

Hosokawa, K., Iyemori, T., Yukimatu, A. S., and Sato, N.: Source of field-aligned irregularities in the subauroral $\mathrm{F}$ region as observed by the SuperDARN radars, J. Geophys. Res., 106, 24713-24731, 2001.

Huber, M.: HF radar echo statistics and spectral studies using SuperDARN, M.Sc. Thesis, University of Saskatchewan, 1999.
Kane, T. A. and Makarevich, R. A.: HF radar observations of the $\mathrm{F}$ region ionospheric plasma response to Storm Sudden Commencements, J. Geophys. Res., 115, A07320, doi:10.1029/2009JA014974, 2010.

Kane, T. A., Makarevich, R. A., and Devlin, J. C.: HF radar observations of ionospheric backscatter during geomagnetically quiet periods, Ann. Geophys., 30, 221-233, doi:10.5194/angeo-30221-2012, 2012.

Koustov, A. V., Sofko, G. J., André, D., Danskin, D. W., and Benkevitch, L. V.: Seasonal variation of HF radar F region echo occurrence in the midnight sector, J. Geophys. Res., 109, A06305, doi:10.1029/2003JA010337, 2004.

Kumar, V. V., Makarevich, R. A., Kane, T. A., Ye, H., Devlin, J. C., and Dyson, P. L.: On the spatiotemporal evolution of the ionospheric backscatter during magnetically disturbed periods as observed by the TIGER Bruny Island HF radar, J. Atmos. Sol.-Terr. Phys., 73, 1940-1952, 2011.

Liu, H.: Study of the high-latitude ionosphere with the Rankin Inlet PolarDARN radar, M.Sc. Thesis, University of Saskatchewan, available at: http://hdl.handle.net/10388/etd-03232010-114923 (last access: 17 February 2014), 2010.

Milan, S. E., Yeoman, T. K., Lester, M., Thomas, E. C., and Jones, T. B.: Initial backscatter occurrence statistics from the CUTLASS HF radars, Ann. Geophys., 15, 703-718, doi:10.1007/s00585-997-0703-0, 1997.

Milan, S. E., Yeoman, T. K., and Lester, M.: The dayside auroral zone as a hard target for coherent HF radars, Geophys. Res. Lett., 25, 3717-3720, 1998.

Mori, D. and Koustov, A. V.: SuperDARN cross polar cap potential dependence on the solar wind conditions and comparisons with models, Adv. Space Res., 52, 1155-1167, doi:10.1016/j.asr.2013.06.019, 2013.

Ruohoniemi, J. M. and Baker, K. B.: Large-scale imaging of highlatitude convection with Super Dual Auroral Radar Network HF radar observations, J. Geophys. Res., 103, 20797-2081, 1998.

Ruohoniemi, J. M. and Greenwald, R. A.: Rates of scattering occurrence in routine HF radar observations during solar cycle maximum, Radio Sci., 32, 1051-1070, 1997.

Tsunoda, R. T.: High latitude irregularities: A review and synthesis, Rev. Geophys., 26, 719-760, 1988.

Wild, J. A. and Grocott, A.: The influence of magnetospheric substorms on SuperDARN radar backscatter, J. Geophys. Res., 113, A04308, doi:10.1029/2007JA012910, 2008. 